\title{
Apresentação. Para além da distinção? DESAFIOS À ABORDAGEM BOURDIEUSIANA DA FORMAÇÃO SOCIAL DO GOSTO
}

\author{
Maria Celeste MIRA* \\ Edison Ricardo BERTONCELO**
}

\section{Gosto não se discute?}

Por que gostamos do que gostamos? Por que rejeitamos o que rejeitamos? As respostas a tais questões são reveladoras da tensão entre concepções opostas sobre a formação do gosto, ora entendido "como um engajamento criativo, espontâneo com um objeto cultural", ora visto como "algo cujo resultado é pré-determinado" (STEWART, 2013, p.3) Esse elemento tensionador estrutura os debates nas Ciências Sociais que, contrariando a noção de senso comum segundo a qual gosto não se discute, têm buscado tematizar os condicionantes sociais do gosto e seu lugar nos processos de produção de desigualdades, na construção de fronteiras sociais e simbólicas e na formação de grupos. Uma rápida passada pelos debates sociológicos travados recentemente sobre o tema indica haver uma profunda discordância entre as abordagens quanto à crescente individualização ou, ao contrário, à persistente diferenciação e estratificação dos gostos e estilos de vida.

Por um lado, para Vandenberghe (2014), a tese da individualização proposta por Beck e Giddens (2002) sugere que:

[...] sob as condições da alta modernidade, os indivíduos... cada vez mais estão livres... não só dos constrangimentos culturais, tais como a religião, a tradição, a moralidade convencional, a incondicional crença na validade da ciência; como também dos constrangimentos estruturais, tais como classe, status, nação, gênero e família nuclear. (VANDENBERGHE, 2014, p.296).

PUC-SP - Pontifícia Universidade Católica de São Paulo. Faculdade de Ciências Sociais da PUC/SP. Departamento de Antropologia. São Paulo - SP - Brasil. 05014-001 - celestemira@gmail.com. https://orcid.org/0000-0002-1073-3297.

* USP - Universidade de São Paulo. Faculdade de Filosofia, Letras e Ciências Humanas. São Paulo - SP - Brasil. 05508-010 - edison.bertoncelo@usp.br. https://orcid.org/0000-0002-6771-0563. 
Em função da elevação das condições gerais de vida, da intensificação dos fluxos de mobilidade geográfica e da crescente disponibilidade de formas alternativas de identidade, preocupações de status e identidades de classe dariam lugar a um novo regime de construção do eu baseado na reflexividade, em que os indivíduos seriam crescentemente responsáveis pela construção de trajetórias de vida em termos de uma biografia do eu. Como resultado de que, sob tais condições, "não temos escolha senão escolher", gostos e estilos de vida (entendidos como "conjuntos mais ou menos integrados de práticas que um indivíduo abraça") dariam forma material a uma "narrativa particular da autoidentidade". (GIDDENS, 2002, p.79)

Em outra vertente da tese da individualização, Bernard Lahire (2016) argumenta que os indivíduos são portadores de um conjunto heterogêneo de disposições e de competências diferencialmente ativadas em diversos contextos de ação. Por isso, em lugar de estilos de vida internamente coerentes que supostamente caracterizam grupos de indivíduos (ex. classes sociais), teríamos perfis culturais dissonantes, produtos da aplicação de princípios de escolha distintos conforme $o$ domínio e o contexto considerados. Conforme o autor:

[...] as variações intraindividuais de comportamento cultural são o produto da interação entre a pluralidade de disposições e competências culturais incorporadas (assumindo a pluralidade de experiências de socialização em questões culturais), de um lado, e, de outro, a diversidade de contextos culturais... em que os indivíduos têm que fazer 'escolhas'[...]. (LAHIRE, 2016, p.110).

Lahire (2003) propõe uma sociologia ao nível individual que visa a investigar o social em sua forma individualizada. Dessa perspectiva, cada indivíduo é visto como o portador de uma pluralidade de disposições e competências, agindo em uma pluralidade de contextos. As práticas são entendidas como o produto de um mecanismo que liga e desliga, ativa e inibe tais disposições e competências de acordo com o contexto (por exemplo, onde, quando e com quem se está). Portanto, embora não desconsidere a existência de variações entre grupos de indivíduos no que se refere a gostos e práticas culturais, as variações intraindividuais seriam sociologicamente mais pertinentes por revelarem essa heterogeneidade de disposições e a pluralidade de contextos em que são ativadas.

Por outro lado, estudos evidenciam que gostos, práticas culturais e estilos de vida são socialmente estratificados e diferenciados, revelando, portanto, padrões que dificilmente podem ser explicados adequadamente pelas teses da individualização. $\mathrm{Na}$ conclusão a uma coletânea de estudos voltados para a investigação comparada da "estratificação social do consumo cultural", Tak Wing Chan - que escreveu um conjunto de artigos com John Goldthorpe reafirmando a importância de se preservar a distinção analítica weberiana entre classe e status na investigação empírica da 


\section{Apresentação. Para além da distinção? \\ Desafios à abordagem bourdieusiana da formação social do gosto}

distribuição de chances de vida (CHAN; GOLDTHORPE, 2004, 2007) - argumenta que o "consumo cultural nas sociedades contemporâneas permanece estruturado e estratificado socialmente" e, portanto, não "perdeu seus suportes na estrutura social" (CHAN, 2010, p.233-234, [tradução nossa]).

Partindo de uma abordagem distinta, o estudo de Bennett et al. (2009) demonstrou de forma similar que a padronização das práticas culturais (em termos de gosto, participação e conhecimento) está relacionada com fatores tão diversos como escolaridade, renda, posição de classe, idade e gênero. ${ }^{1}$ Por sua vez, em relação ao argumento de Lahire (2003) quanto às variações intraindividuais, Jarness (2015) sugere que a ênfase na dissonância dos perfis culturais tende a esconder a coerência e homogeneidade das disposições, na medida em que diferentes bens e práticas (em termos de forma e conteúdo) podem ser apropriados de uma maneira similar. Ou seja, heterogeneidade ao nível do opus operatum e homogeneidade ao nível do modus operandi.

\section{O legado clássico e seus desdobramentos contemporâneos}

Os debates sobre os padrões na distribuição social dos gostos e práticas culturais chamam atenção para a relação entre estratificação social, cultura e poder, o que está longe de ser uma novidade nas Ciências Sociais. Um conjunto de autores dos primeiros tempos da Sociologia se deram conta desta problemática. Um de seus pilares, Max Weber (1991 [1922]), ao estabelecer a diferença entre classe, partido e estamento ou status (stände em alemão), percebe que, neste último caso, a superioridade social se manifesta por meio de um conjunto de privilégios, da honorabilidade, de um modo de vida peculiar independentemente do poder econômico (classe) ou político (partido). Os estilos de vida, de acordo com o autor, sempre teriam origem em estamentos, estando relacionados, portanto, não a classes, mas a grupos de status.

Werner Sombart (2009), contemporâneo e interlocutor de Weber, procurou entender o papel do comércio de bens de luxo na constituição da sociedade capitalista. Como observou Glaucia Villas Bôas (2001), para o autor, a secularização do amor e as decorrentes mudanças na relação entre os sexos (não no casamento, mas fora dele), no papel da mulher, em particular, da cortesã e do comportamento nas sociedades de corte, constituíram fatores essenciais ao impulso inicial da nova sociedade:

\footnotetext{
1 Para um argumento similar em referência à distribuição das práticas culturais e preferências musicais na sociedade brasileira, ver Bertoncelo, 2019.
} 
Para Sombart decididamente não é o afã aquisitivo que gera manufaturas, mas o consumo de um bem, a ser utilizado talvez por poucas horas, para suprir um capricho e prazer passageiro. Este consumo, sim, leva à proliferação das fábricas em torno das cortes das cidades, a começar pela importante indústria da seda, o melhor exemplo de uma manufatura que servia ao luxo. Se o ascetismo, a retenção, o ganhar mais e ser mais rentável tornam-se uma virtude para o burguês protestante, em Sombart, em visível contraste com Weber, é na futilidade, na vain ostentation, no supérfluo, que se encontra o valor que engendra o grande crescimento da ordem capitalista. (VILLAS BÔAS, 2001, p.191).

Outro autor que merece ser notado é Georg Simmel (1977[1900]) que, na mesma época, se dedicou a temas como o amor, a aventura, a cultura feminina, entre outros convencionalmente relacionados à esfera da cultura. Em sua obra mais importante, Filosofia do dinheiro, percebe, pelas transformações da cidade de Berlim, que o mundo moderno trazia consigo um novo estilo de vida marcado pela economia monetária, a velocidade, a despersonalização das relações entre os indivíduos, entre outras. Ao analisar o tema da moda, Simmel (1977) a considera produto da divisão em classes. Para o autor, a moda atende à dupla necessidade do indivíduo de diferenciar-se, expressar sua personalidade e, ao mesmo tempo, identificar-se com determinado grupo social. Em relação à estratificação social, o autor pensou o ciclo da moda como decorrente da imitação das classes superiores pelas classes inferiores, resultando na mudança de orientação das primeiras para outras expressões de status, novas imitações e assim sucessivamente.

Pode-se acrescentar a essa lista de autores, o economista estadunidense Thorstein Veblen (1985 [1899]), que se notabilizou mais recentemente quando os estudos sobre consumo resgataram de A teoria das classes ociosas sua noção de consumo conspícuo, entendido no sentido de ostentatório, aplicável a todas as classes sociais que não exercem trabalho produtivo, embora sua crítica se dirigisse às emergentes classes de lazer americanas do começo do século XX. Esta perspectiva, por sua vez, é criticada por Norbert Elias (1995; 1990), para quem Veblen (1985) não compreendeu o sistema de despesas das classes honoríficas. Lembrando ser a extensa obra desse teórico alemão rica em articulações entre a cultura e diferentes grupos sociais, basta ressaltar duas de suas obras mais notáveis: O processo civilizador: uma história dos costumes e $A$ Sociedade de corte. Dentre outras coisas, elas revelam, por meio de estudo minucioso sobre a formação e o estilo de vida da nobreza de corte, a importância da dimensão cultural e simbólica da estratificação social, bem como da conquista e manutenção do poder.

No entanto, as reflexões desse conjunto de autores, exceto Max Weber, demoraram a ser incorporadas aos debates das Ciências. Apontando no sentido contrário de A ética protestante e o espírito do capitalismo de Max Weber (1991), a 


\section{Apresentação. Para além da distinção? \\ Desafios à abordagem bourdieusiana da formação social do gosto}

obra mais importante de Werner Sombart (2009), Lujo y Capitalismo publicada em 1913, permaneceu por muitas décadas à sua sombra. Mesmo no caso de Weber, é de se notar que seus conceitos de status e estilo de vida não foram os mais destacados na leitura de sua obra. Hoje bastante celebrado, Georg Simmel (1977), transitando por temas inusitados para a época, pelos campos da Sociologia, da Psicologia e da Filosofia, teve dificuldade, inclusive, para se incorporar às instituições acadêmicas de seu tempo. Como seus antecessores, Norbert Elias $(1995,1990)$ também teve reconhecimento tardio. Publicado pela primeira vez em 1939, O processo civilizador passou despercebido, tendo chamado atenção somente trinta anos mais tarde, em 1969, quando foi republicado no mesmo ano de $A$ sociedade de corte. Isto se deve ao fato de que, no período em que escreveram, do final do século XIX até a metade do século XX, os objetos privilegiados pelo debate sociológico eram o trabalho e não o ócio, a produção e não o consumo, a economia e não a cultura.

Essa perspectiva muda substancialmente com a aparição da obra de Pierre Bourdieu (2008 [1979]). Munido de robusta pesquisa empírica e poderoso arsenal analítico, o sociólogo francês colocou a dimensão cultural no centro dos debates sobre desigualdades de classe. Sua obra $A$ Distinção: crítica social do julgamento tornou-se a principal referência nos debates recentes sobre os condicionantes do gosto e a construção de fronteiras sociais e simbólicas. Um de seus grandes méritos foi vincular a dimensão da cultura, enquanto fonte de poder, e a dinâmica de reprodução das classes sociais, fazendo delas um tópico incontornável do debate acadêmico. Pode-se agregar-lhe outros tópicos, questioná-lo, ultrapassá-lo, mas não se pode desconhecê-lo, nem quando se discute o tema da cultura, nem quando o problema é a formação de grupos sociais.

A abordagem construída por Pierre Bourdieu (2008) fornece um aparato analítico-conceitual que nos permite apreender a dimensão simbólica da relação entre cultura e classes sociais. Tal aparato inclui os conceitos de espaço social, habitus, capital e estilos de vida. O espaço social é, simultaneamente, uma estrutura de relações objetivas que está na origem dos esquemas de percepção, classificação e ação (habitus) que orientam a prática, e um conjunto de lugares estratégicos a partir dos quais os agentes lutam pela apropriação e valorização dos capitais (econômico, cultural, social e simbólico) e pela imposição de princípios de classificação e de divisão do mundo social (SALLUM; BERTONCELO, 2017).

O cerne do argumento bourdieusiano reside na noção de homologias ou de correspondências estruturais entre "dois conjuntos de relações, o espaço dos estilos de vida e o espaço das posições sociais ocupadas pelos diferentes grupos" (WACQUANT, 2005, p.155 apud LIZARDO; SKILES, 2016), que resulta da dupla capacidade do habitus de produzir práticas e juízos sobre as práticas. Desse ponto de vista, estilos de vida, conjuntos "de práticas e de consumos que tendem a ser adotados pelo mesmo indivíduo ou grupo" (DUVAL, 2017), são vistos como 
retraduções simbólicas - na lógica dos diferentes campos - de diferenças objetivas (BOURDIEU, 2008). Consequentemente, as diferentes classes e suas frações se distinguiriam umas das outras tanto no plano material quanto no plano simbólico, quer dizer, em termos do montante, da composição e da modalidade de apropriação de diferentes tipos de capitais, e de estilos de vida internamente coerentes (e relacionalmente referidos), produtos da transponibilidade do habitus.

Desse ponto de vista, o gosto - como a "propensão e aptidão para a apropriação (material e/ou simbólica) de uma classe determinada de objetos ou de práticas classificadas e classificantes" e, portanto, "a fórmula geradora que se encontra na origem do estilo de vida" (BOURDIEU, 2008, p.165) - é um marcador privilegiado de classe e um princípio da estratificação social, ainda que, aos olhos de seus portadores, possa ser a (mera) materialização de reivindicações identitárias. ${ }^{2}$

Vê-se, portanto, que o espaço simbólico não é um reflexo da luta de classes. Ao invés, é o lugar onde as lutas de classe são travadas. Como explica Bourdieu (2008), as lutas entre as classes e suas frações são disputas pelo estabelecimento dos princípios de hierarquização dos estilos de vida.

\section{Formação de grupos, capital cultural e distinção}

Um dos principais legados da obra de Bourdieu é a concepção de cultura como um capital, suscetível de ser acumulado, transmitido e convertido em outros capitais, sendo, por isso, um recurso nas lutas em torno da (re)produção de fronteiras sociais e simbólicas (LAMONT; MOLNAR, 2002). Originalmente empregado por Bourdieu (1982b) e colaboradores em suas pesquisas sobre educação para explicar as taxas diferenciais de sucesso escolar entre as crianças de origens sociais privilegiadas (em função da transmissão familiar das disposições e competências que facilitavam o entendimento da linguagem pedagógica, a satisfação das exigências de avaliação e a apropriação dos conteúdos escolares), o conceito de capital cultural passou a ser empregado posteriormente tanto como um princípio autônomo de diferenciação social ao lado do capital econômico (multidimensionalidade do espaço social) quanto como disposições para a apropriação (entendida como) legítima dos bens e práticas mais legítimos (ou seja, daquilo que é visto como digno de ser apropriado).

2 Como já tivemos oportunidades de ressaltar, "a ênfase na reflexividade na 'modernidade tardia' poderia expressar as orientações de grupos sociais específicos (daqueles que, de fato, possuem as disposições e os recursos necessários para fazer das 'trajetórias de vida' a materialização de projetos do eu reflexivamente construídos), e não uma condição geral de um 'novo' período histórico." (BERTONCELO, 2013, p.186). Para uma discussão mais ampla, conferir Savage, 2000; Skeggs, 2004. 


\section{Apresentação. Para além da distinção? \\ Desafios à abordagem bourdieusiana da formação social do gosto}

Nas últimas décadas, houve um enorme avanço na pesquisa comparada sobre a formação do capital cultural e processos de distinção (PRIEUR; SAVAGE, 2011, 2013). Os resultados são controversos.

De um lado, alguns estudos sublinham a pouca relevância das hierarquias culturais nos processos de distinção fora do contexto francês (HALLE, 1991; LAMONT; MOLNAR, 1992). Outros sustentam que, no bojo de mudanças históricosociais relacionadas com a ampliação da oferta de bens culturais e a maior tolerância das elites com valores e normas culturais distintos, emergiriam novos repertórios de práticas e gostos culturais, "marcados tanto pela maior amplitude de gostos e participação quanto pela disposição em transgredir fronteiras previamente bem delimitadas entre gêneros e bens culturalmente hierarquizados". (KARADEMIR; WARDE, 2016, p.77). Ganhava corpo, assim, a tese do onivorismo cultural, que, ao menos em sua versão mais radical, sugere a crescente erosão das hierarquias culturais ou simbólicas e entende que o gosto cultural teria pouca relevância para a delimitação de fronteiras simbólicas (PETERON, 2005; PETERSON; SIMKUS, 1992). A partir da análise de dados sobre gostos musicais com base em dois surveys conduzidos em 1983 e 1992, Richard Peterson (2005) observou uma tendência ao aumento de repertórios musicais que incluíam preferências pela música clássica ou pela ópera ao lado de preferências por gêneros musicais menos consagrados, como o rock. Tais repertórios, constituídos por preferências que cruzavam fronteiras culturais estabelecidas, encontrariam nos grupos mais escolarizados seus portadores privilegiados e marcariam uma mudança significativa em relação ao suposto esnobismo materializado na estética kantiana do desinteresse, subjacente ao gosto burguês e sua rejeição pelo gosto popular (PETERSON; KERN, 1996).

De outro lado, diversos estudos sublinham a necessidade de se fazer uma utilização relacional e histórica do conceito de capital cultural, que considere as disputas entre os agentes nos diferentes campos sociais sobre o que é digno de ser apropriado, transmitido e monopolizado, e que pode produzir ganhos para aqueles que o controlam (LAREAU; WEININGER, 2003). O uso desta perspectiva relacional nos leva a explorar os tipos de práticas culturais que são reconhecidas e consagradas em determinado momento, por quais grupos e indivíduos, e as consequências disso (ex. dominação simbólica) para aqueles que não controlam os instrumentos de apropriação desses bens ou práticas consideradas dignas de apropriação/monopolização (PRIEUR; SAVAGE, 2011).

Há tempos, Holt (1998) nos alertou para os riscos de uma leitura substancialista da abordagem bourdieusiana. Na Sociologia norte-americana, por exemplo, tal leitura se materializava num enfoque que indagava:

[...] se a articulação particular do capital cultural na sociedade parisiense de 1960, objetivada primariamente nas artes legítimas e incorporada na apreciação estética 
formal, vale para os Estados Unidos contemporaneamente [...]. A falha nesse argumento é que as artes constituem apenas uma pequena fração do universo dos campos de consumo que podem ser alavancados para a reprodução social. Ao enfocarem exclusivamente o campo artístico, esses estudos subestimam as atividades para as quais as elites culturais norte-americanas dedicam a maior parte de suas energias fora do trabalho, como alimentação, decoração de interiores, férias, moda, esportes, leitura, hobbies e eventos sociais. (HOLT,1998, p.6 [tradução nossa]).

Ou seja, a observação da ausência de uma relação significativa entre gostos e práticas ligados à alta cultura ou à cultura tradicional, de um lado, e o pertencimento às classes superiores, de outro, teria levado alguns autores a sentenciar a inadequação do aparato analítico bourdieusiano para apreender as dinâmicas culturais nas sociedades contemporâneas e seu papel na diferenciação social e na produção de desigualdades (CHAN, 2010).

Embora o debate sobre a emergência do onívoro cultural tenha chamado atenção para um fato amplamente documentado, relacionado com o declínio da cultura tradicional, sobretudo entre os mais jovens, há diversos problemas na tese do onivorismo, especialmente no que se refere às tendências de se definir a priori os conteúdos da alta, média e baixa culturas. Isso tende a fixar o conteúdo do capital cultural, e a ignorar a distinção entre modus operandi e opus operatum e, portanto, "o ponto metodológico de que os gostos culturais e seus significados simbólicos não podem ser lidos diretamente dos bens culturais para os quais as pessoas relatam preferências" (JARNESS, 2015, p.). Em outras palavras, desconsidera-se a modalidade da prática, de que os mesmos bens e práticas são percebidos e apropriados diferentemente e, portanto, que as pessoas podem gostar das mesmas coisas de modos totalmente diferentes, o que implica que gostar das mesmas coisas não significa ter os mesmos gostos (JARNESS, 2015). Nas sociedades contemporâneas, caracterizadas pela ampliação da esfera de produção, difusão e de consumo de bens simbólicos e das oportunidades de escolhas estéticas, os processos de distinção dependem cada vez mais de como os bens são apreciados e apropriados do que propriamente do que é apreciado e apropriado (HOLT, 1998; PRIEUR; SAVAGE, 2013), com exceção, talvez, das elites ou das classes altas, capazes de sustentar estilos de vida marcados pela exclusividade dos bens e práticas que $o$ compõem, em função das raríssimas condições sociais de produção dos gostos e disposições subjacentes, caracterizadas pela transmissão e acumulação de elevados volumes de capital econômico, cultural, social e simbólico (PULICI, 2011, 2014; ROSATTI, neste volume).

Muitos esforços têm sido feitos na tentativa de operacionalizar essa leitura relacional e histórica da formação do capital cultural e dos processos de distinção. 


\section{Apresentação. Para além da distinção? \\ Desafios à abordagem bourdieusiana da formação social do gosto}

Uma abordagem metodológica bastante comum consiste no uso combinado de técnicas qualitativas e quantitativas (grupos focais, entrevistas, surveys) em conjunção com um método (sobretudo a Análise de Correspondências Múltiplas) que possibilite reconstruir indutivamente os padrões de distribuição das práticas culturais (gostos, conhecimento, participação) dos agentes em diferentes domínios da vida social (música, artes, alimentação, esportes etc.). Nesse caso, parte-se da reconstrução do espaço dos estilos de vida (na maior parte dos estudos, são empregados predominantemente indicadores de consumo cultural) para, então, observar-se como as oposições simbólicas se correlacionam com propriedades dos agentes sociais (indicadores de capital econômico e cultural, ocupação, sexo, idade etc.) (BENNETT et al. 2009). Por vezes, é feito o movimento oposto, partindo-se da reconstrução do espaço social (em suas dimensões relacionadas com o volume, composição e trajetórias dos capitais) para, então, observar-se como se distribuem as práticas culturais ou, mais amplamente, os usos do tempo livre no espaço assim construído (PEREIRA, 2005). ${ }^{3}$

A comparação dos resultados desses estudos permite afirmar que o conteúdo do capital cultural é, como esperado, variável, embora o conceito permita apreender a produção e transmissão de vantagens e de monopolização de oportunidades sociais com base na posse de cultura. Há evidências do declínio da cultura tradicional ou clássica nos países em que o manejo dos instrumentos necessários à sua apreciação e apropriação gozava de elevado reconhecimento e legitimidade, declínio esse impulsionado por dinâmicas geracionais (ROOSE, 2015; SAVAGE et al., 2013; GRIPSRUD; HOVDEN; MOE, 2011; BENNETT et al., 2009) ${ }^{4}$, por mudanças nas relações de força entre frações de classe (com peso crescente do capital econômico) (DUVAL, 2015), por transformações nas instâncias de consagração e de legitimação (ver adiante), entre outros. Ao mesmo tempo, tais estudos sublinham a provável formação de um capital cultural emergente e de novas formas de distinção, com base em evidências relacionadas com a construção de repertórios de práticas e gostos culturais marcados pelo ecletismo e pelo manejo informado das classificações culturais (BENNETT et al., 2009), por modos irônicos e distanciados de apropriação (em oposição, conforme se diz, à estética kantiana do desinteresse) (HANQUINET; ROOSE; SAVAGE, 2014) e por uma orientação cosmopolita (em oposição ao localismo) capaz de deslocar o agente, no que se refere aos condicionantes das práticas e dos gostos, para fora dos enquadramentos nacionais (PRIEUR; SAVAGE, 2013)

\footnotetext{
3 Ver o conjunto de estudos publicados em The Routledge Companion to Bourdieu's Distinction por Coulangeon; Duval (2015).

4 Reeves (2016) discute as dificuldades para se diferenciar os efeitos de idade, período e coorte na investigação das mudanças das práticas culturais.
} 
A discussão sobre as novas formas de distinção e do capital cultural emergente faz ressurgir a tese do onivorismo cultural, mas sob outra ótica, "como um exemplo de uma disposição estética que se adapta às novas regras do jogo no campo cultural" (STEWART, 2013, p.93). As hierarquias de gosto mudaram, é verdade, mas não desapareceram. É o que se pode depreender dos argumentos de Bennett et al. (2009, p.177-178, grifos nossos) referindo-se à recente formação das classes médias britânicas: as "classes médias educadas buscam posicionar-se através da demonstração de competência em manejar uma diversidade de produtos culturais em um contexto em que conhecimento, informação e mídia proliferam" ao invés de buscarem diferenciar-se das classes manuais pelo "controle de um cânone cultural fixo". Por isso, em suas conclusões, os autores do estudo argumentam que a formação das fronteiras de classe depende menos da "seleção do conteúdo cultural do que da orientação em relação ao consumo cultural." Isso significa que a "expressão dominante do capital cultural" reside na "adoção de uma orientação onívora", cujo princípio da abertura à diversidade possibilita a apropriação seletiva de "formas culturais emergentes e contemporâneas" (BENNETT et al, 2009, p.254).

Assim entendido, o onivorismo cultural não nos parece incompatível com a hipótese das homologias:

[...] essa 'capacidade tolerante' para transpor a disposição estética para domínios e bens 'vulgares' ou, pelo menos, para longe das práticas simbolicamente consagradas[...] é, na verdade, o que está na base da chamada 'abertura à diversidade', princípio subjacente ao onivorismo cultural. (BERTONCELO, 2019, p.).

Ainda assim, a discussão em torno da emergência do onívoro cultural indica a centralidade da dimensão simbólica das lutas de classe. Como argumentou Bourdieu (2008, p.40), "a capacidade para constituir esteticamente objetos quaisquer ou, até mesmo, 'vulgares' (por terem sido apropriados, esteticamente ou não, pelo 'vulgar') ou aplicar os princípios de uma estética 'pura' nas escolhas mais comuns da existência comum" constituía um dos trunfos culturais mais importantes da fração de classe intelectualizada nas disputas pela imposição dos modos legítimos de viver na sociedade francesa por ele investigada.

Por isso, gostos, práticas, conhecimentos e disposições que operam como capital cultural são o produto dessas disputas entre as diferentes classes e suas frações. Consequentemente, mudanças no conteúdo do capital cultural estariam intimamente imbricadas a transformações nesse balanço de poder. Em um artigo recente, Delphine Serre e Anne-Catherine Wagner (2015) argumentam que as mudanças no espaço social francês contemporâneo no bojo do prolongamento da escolarização, da diversificação da oferta cultural e da crescente internacionalização 


\section{Apresentação. Para além da distinção? \\ Desafios à abordagem bourdieusiana da formação social do gosto}

de ideias e elites alteraram as condições de acesso ao capital cultural e, portanto, seu papel na produção de desigualdades e na formação de fronteiras sociais. Embora a reprodução da classe dominante dependa crescentemente do capital cultural institucionalizado, com maior valor para as credenciais educacionais obtidas nas grandes escolas superiores voltadas à formação para o mundo gerencial e financeiro, sua aquisição continua sendo tributária da incorporação de certas competências e disposições na família e na escola (conhecimento de outras línguas, experiências no exterior, familiaridade com outras culturas), cujas condições de produção estão ligadas à acumulação de capital econômico. ${ }^{5}$

\section{Mundialização da cultura, tecnologias de informação e comunicação e os desafios ao sistema teórico de Bourdieu}

Os estudos da seção anterior procuram compreender uma série de transformações recentes que alteraram substancialmente o cenário cultural a partir do qual Bourdieu (2008) escreveu A Distinção. Como vimos, porém, grande parte das questões já colocadas e a principal conclusão a que se chegou - a de que não importa apenas o quê, mas também como se consome determinado bem simbólico é algo que pode ser compreendido a partir da própria teoria bourdieusiana. Dizia o autor que nada diferenciava mais as classes e frações de classe do que a aptidão para consumir de forma legítima as obras legítimas. Em vários momentos de sua obra, o autor frisa a importância de como se dá a apropriação relacionando o maior grau de legitimidade ao volume de capital cultural do agente, especialmente, na sua forma incorporada, resultado da antiguidade de pertencimento familiar à classe dominante, um valor essencialmente nobre adotado pela burguesia ascendente. Mais ainda, Bourdieu (2008) mostra como justamente aos mais dotados de capital cultural é reservada a possibilidade de fazer as escolhas mais ousadas e, portanto, mais arriscadas.

Esse tipo de prática cultural marcada pelo que Bourdieu (2008) denominou de disposição estética, ou seja, o interesse desinteressado pela arte e pela alta cultura em geral, era sinônimo de bom gosto na sociedade francesa dos anos 1960/70. A sistemática bourdieusiana que situa o gosto de classe como definidor das práticas culturais e dos estilos de vida pressupõe, portanto, a existência de um determinado

\footnotetext{
5 De forma similar, Duval (2015) argumenta que a mudança no equilíbrio entre os mercados ampliados e os mercados de distribuição restrita (no campo do cinema), em detrimento destes últimos, decorreu em parte de alterações das relações de poder entre as frações dominadas (intelectuais) e dominantes (burguesas) da classe dominante, em benefício destas últimas. "Hoje essas [frações de] classes têm menor necessidade do gosto intelectual do que nas décadas do pós-guerra simplesmente porque não há desafios relevantes a sua dominação econômica." (DUVAL, 2015, p.106).
} 
gosto legítimo. Formado historicamente nas sociedades de corte europeias e assimilado pela alta burguesia ou burguesia de tradição, na expressão do autor, trata-se de um conjunto restrito e requintado de modos de ser e de se comportar, em particular, de formas de percepção do campo da arte em vias de autonomização. A formação do gosto legítimo ocorre pari passu ao enobrecimento das Belas Artes. Autores como Williams (1969) e o próprio Bourdieu (1982a) explicam a dinâmica histórica que levou à constituição da ideia de arte como realidade superior, do artista como gênio criador, em suma, do campo da arte como campo da forma e do estilo, como lugar de expressão da subjetividade do artista, alheio a qualquer interesse. O processo se inicia no Renascimento, percorre todo o período moderno, durante o qual, embora a serviço das cortes, o artista se liberta das corporações de ofício, deixando de ser artesão - a pintura, por exemplo, deixa de ser considerada trabalho manual -, passando a exercer atividade e ser ele mesmo honorável. Com a posterior autonomização do campo, a arte já constituía em torno de si a aura de que precisava para sobreviver no mundo burguês. (WARNKE, 2001).

A ideia da arte pela arte, ou seja, a afirmação do campo da arte como lugar de atividade desinteressada e superior a todas as outras esferas ligadas às necessidades da vida, na visão de Bourdieu (1982a), representava a tentativa dos artistas, recémemancipados do jugo de seus mecenas, de criar uma espécie de fronteira distintiva em relação ao nascente mercado de bens culturais que os submeteria ao julgamento de um público amplo e desconhecido. A dominância dessa concepção de arte e do correspondente gosto legítimo tem sido sustentada, desde o início do século XIX, de acordo com o autor, pela manutenção de uma esfera restrita da arte separada da esfera ampliada do mercado de bens simbólicos, ou seja, da indústria cultural. No entanto, sua permanência depende, pelo menos, de dois fatores: da manutenção da concepção do campo da arte como realidade superior; e da contínua interiorização de sua equivalência ao gosto legítimo ou bom gosto no seio das classes médias e populares.

Pode-se dizer que a fronteira entre arte e mercadoria se manteve incólume até os anos 60 do século XX. Funcionava, então, na expressão de Andreas Huyssen (1997), uma espécie de grande divisor: de um lado, a vanguarda, de outro, o kitsch. A pop art anuncia o fim dessa era - que se consolidará com o pós-modernismo -, consagrando artistas e repertórios oriundos da cultura de massas na esfera culta e restrita das galerias de Nova York que, naquele momento, já havia roubado de Paris o título de principal polo e mercado de arte do mundo. Depois da pop art, não há mais movimentos artísticos. Ela é a última vanguarda. De acordo com Huyssen (1997) ocorre, então, uma dispersão das práticas artísticas e culturais. Cada vez mais, os artistas transitam entre os mercados eruditos e de massa. Isto não quer dizer que a experiência artística tenha se democratizado, quer dizer apenas que a contraposição entre arte e mercadoria ou arte e técnica não é mais possível. Abre-se, 


\section{Apresentação. Para além da distinção? \\ Desafios à abordagem bourdieusiana da formação social do gosto}

assim, uma fenda no campo da arte que dificulta a fixação do gosto legítimo na esfera erudita, deslocando-o, possivelmente, para outros que também impliquem raridade.

Os avanços da indústria do entretenimento, tanto em termos econômicos quanto estéticos, permitem a criação de suas próprias instâncias de consagração e legitimação, elegendo novos modelos a serem imitados: as celebridades. A arte pop é apenas um aspecto da cultura pop. A cultura pop é jovem, popular e internacional. Ela é parte dos movimentos identitários dos anos 1960/70, o estudantil, o negro, o feminista, o gay etc. Ela inaugura no plano internacional um novo popular, o popular de massa, midiático, de mercado, do espetáculo, do entretenimento. A cultura pop, enfim, é global. De forma desigual entre os Estados-Nação, a cultura pop faz explodir o mercado global de cultura, tanto em virtude das tecnologias de comunicação que aproximam cada vez mais produtores e consumidores, quanto pela crescente diversificação das ofertas e dos usos gerados pela hiper-segmentação das reivindicações de reconhecimento identitário.

A partir dos anos 1960, o cenário cultural começa a se orientar em direção à globalização ou mundialização da cultura (ORTIZ, 1994). Este processo desloca a constituição das referências identitárias individuais e coletivas, portanto, das práticas sociais e culturais, do plano nacional para o global. A nação não deixa de ser referência importante para a construção das identidades individuais e coletivas. No entanto, não é mais a única, nem tão importante como foi na modernidade europeia clássica. Na situação de mundialização, suas fronteiras são ultrapassadas com certa facilidade por meio de tecnologias de comunicação e transporte cada vez mais avançadas. Isto não significa necessariamente americanização ou homogeneização cultural. Embora os Estados Unidos tenham tido a maior fatia do mercado global no século XX, a mundialização da cultura pode ser mais bem compreendida como um processo de expansão da modernidade capitalista, ou seja, como um novo padrão (pattern) de cultura, caracterizado, sobretudo, pela mobilidade e pela aceleração do tempo. (HARVEY, 1993; ORTIZ,1994).

Por sua vez, o mercado global se realiza por meio da segmentação, aproximando e distanciando indivíduos para além das fronteiras nacionais. Os bens e as mercadorias, as imagens e os imaginários circulam pelo mundo visando os públicos e consumidores de determinados segmentos. De um lado, essa dinâmica dispersa ainda mais os gostos e as práticas culturais, uma vez que a mundialização ocorre também por interação com os diferentes locais. De outro, ela aproxima indivíduos que, apesar da distância geográfica, têm o mesmo estilo de vida. O que os aproxima ou diferencia são padrões socioeconômicos, identidade de gênero, etnicidade, faixa etária ou fases da vida adulta, como casamento, criação dos filhos etc. Isto tende a formar segmentos de consumidores mundializados, embora não signifique necessariamente que tenham sido criados artificialmente pelo mercado. Historicamente, nos 
séculos XIX e XX, observa-se uma circularidade entre movimentos socioculturais e segmentos de mercado (MIRA, 2001).

A reorganização da vida social em uma situação de mundialização da cultura coloca uma problemática ainda mais complexa. Bourdieu (1982a, 1982b, 2008) concebe a relação entre gostos de classe e estilos de vida a partir de um contexto nacional. Não é por acaso que, em sua teoria, a instituição escolar ocupe um papel central. Como veremos, o Estado-Nação e a instituição escolar são mutuamente dependentes. Por este motivo, o segundo alicerce para a manutenção do gosto legítimo atrelado à esfera restrita da arte e da cultura ilustrada relaciona-se ao sistema escolar. Louis Althusser já chamara atenção para seu aspecto "ideológico" e Michel Foucault para o seu caráter disciplinar. Para Bourdieu (1982b), a escola é responsável por algo ainda mais crucial: a integração lógica da sociedade moderna.

Para aprofundar esta problemática, é preciso retomarmos dois pontos fundamentais do pensamento bourdieusiano. O primeiro é que, para o autor, todo o processo de socialização do agente é profundamente marcado pela sua experiência de classe ou fração de classe, bem como pelo tipo de trajetória, ascendente ou descendente, que ela descreve no momento histórico considerado. $\mathrm{O}$ segundo ponto é que todas as categorias a partir das quais os atores sociais apreendem e classificam o mundo são totalmente arbitrárias. Os linguistas diriam que, como os fonemas, elas só existem na diferença: o bom é diferente do mau, o bonito do feio e assim por diante. Nesse sentido, a interiorização das categorias de percepção é mais importante do que o conteúdo com o qual serão preenchidas. As categorias de percepção e classificação que são introjetadas pelo agente, por meio da transmissão da família e da escola não representam o seu mundo. Na verdade, elas o constituem, são a base de sua compreensão do mundo e da vida, marcadas por sua origem e suas experiências de classe.

Em Sistemas de ensino e sistemas de pensamento, Bourdieu (1982b) esclarece suficientemente este tópico, polemizando com Émile Durkheim:

É paradoxal que o autor das Formas primitivas de classificação e das Formas elementares da vida religiosa não se tenha dado conta, em seus escritos dedicados à educação, de que, do mesmo modo que a religião nas sociedades primitivas, a cultura escolar propicia aos indivíduos um corpo comum de categorias de pensamento que tornam possível a comunicação. (BOURDIEU, 1982b, p.205).

Embora Durkheim tenha acreditado encontrar nas sociedades primitivas as origens das formas de percepção e classificação, portanto de categorias lógicas, e se ocupasse também do tema da educação no mundo moderno, Bourdieu (1982b) se mostra perplexo diante do fato de que o fundador da Sociologia atribuiu ao sistema escolar apenas a função de integração moral, quando, de fato, ele seria responsável também pela "integração lógica" da sociedade: 


\section{Apresentação. Para além da distinção? \\ Desafios à abordagem bourdieusiana da formação social do gosto}

[...] a escola tende a assumir uma função de integração lógica de modo cada vez mais completo e exclusivo à medida que seus conhecimentos progridem. $\mathrm{Na}$ verdade, os indivíduos "programados", quer dizer, dotados de um programa homogêneo de percepção, de pensamento e de ação, constituem o produto mais específico de um sistema de ensino. (...) Tendo sido moldados segundo o mesmo "modelo" (pattern), os espíritos assim modelados (patterned) encontram-se predispostos a manter com seus pares uma relação de cumplicidade e comunicação imediatas. (BOURDIEU (1982b, p.206).

Para substituir a religião como instituição encarregada da integração lógica da sociedade, o sistema escolar teve que organizar uma nova classificação do mundo apreensível por meio de categorias diferentes: ao invés das vigentes no mundo mágico-religioso, as do pensamento racional. A escola passa a ser responsável pela transmissão, dentre outros, do saber científico e da cultura humanista e erudita. É por meio da escola, de suas categorias e classificações que se difunde o habitus cultivado. Embora menos valorizado do que o adquirido precocemente no ambiente familiar, o capital cultural institucionalizado, conferido pelos conhecimentos adquiridos e certificado pelos diplomas escolares, tem um peso bastante considerável no sistema de lutas de classe simbólicas tal como o concebeu Bourdieu (1982b).

Algo semelhante à passagem da religião para a educação escolar, enquanto instituições responsáveis pela integração lógica da sociedade, pode estar em curso a partir do último quarto do século XX, desafiando todo o edifício teórico bourdieusiano: novas formas de percepção - para além dos novos valores introduzidas pela rápida expansão da informática. Os modos de apropriação dessas tecnologias, ainda embrionárias no período de investigação de $A$ Distinção, têm gerado novas formas de comunicação que, no mínimo, vêm desestabilizando a escola no exercício de sua função de integração lógica da sociedade contemporânea.

Se a cultura pop difundida pelos meios de comunicação de massa tornou porosas as fronteiras entre o erudito e o popular no plano da produção de bens simbólicos, o advento da informática complexificou ainda mais a problemática do gosto legítimo. Em primeiro lugar, já não se trata mais de compreender o comportamento do grande público: o internauta não é apenas consumidor, é usuário de um meio técnico que, ao mesmo tempo, produz e consome informação e comunicação. Em segundo lugar, se a entrada em cena da cultura pop midiática provocou a dispersão das práticas artísticas e culturais, gerando instâncias concorrentes de divulgação, consagração e legitimação, a era da informática traz consigo novas formas de percepção que desafiam ainda mais a formação do habitus cultivado pelo sistema escolar. Beatriz Sarlo (1997) chamou a atenção para o caráter mundial da perda de hegemonia da cultura letrada. Para a autora, estaríamos diante de uma crise da alfabetização, de uma mutação cultural, cuja solução não é a simples 
introdução de computadores ou outros meios eletrônicos nas escolas. A questão é que as habilidades desenvolvidas pela cultura audiovisual são diferentes das exigidas pela escola, como "o raciocínio lógico e matemático abstrato, a expressão linguística e a argumentação [...]." (SARLO, 1997, p.114). A cultura audiovisual procede de maneira oposta. Desde muito cedo, habitua as crianças a ler imagens rápidas, complexas e superpostas, de tal modo que poucos adultos dos dias de hoje conseguem fazer.

Paula Sibilia (2012, p.63) também acredita que a chamada civilização da imagem "implicou certa crise das 'belas artes' da palavra". Tendo a leitura e a escrita como um de seus pilares, a escola, sobretudo após o surgimento das tecnologias digitais, tem sido considerada pelos estudantes como algo extremamente chato, sendo o desinteresse o principal motivo de evasão escolar alegado pelos jovens brasileiros. (SIBILIA, 2012, p.65) No entanto, prossegue a autora, não se pode tratar a questão apenas como déficit de habilidades ou de disciplina, as quais tendem a ser patologizadas como os conhecidos distúrbios: Transtorno Desafiador de Oposição (TOD), Transtorno do Déficit de Atenção com Hiperatividade (TDAH). Os chamados "nativos digitais" são "peritos em opinar, fazer zapping e ler imagens" (COREA, apud SIBILIA, 2012, p.74), embora isto não os prepare para a instituição escolar. Ao contrário,

[...] em vez da interioridade e da concentração requeridas pelo discurso pedagógico, o discurso midiático requer exterioridade e descentramento: recebo informações que não chego a interiorizar - a prova é que, um minuto depois de ter mudado de canal, já não lembro mais o que vi - e devo estar submetido à maior diversidade possível de estímulos: visuais, auditivos, táteis, gustativos. (COREA apud SIBILIA, 2012, p.77).

É curioso notar que Walter Benjamin (1993) já chamara nossa atenção, ao analisar o cinema, para a emergência de uma nova forma de percepção, exatamente, a percepção desatenta. Após mais de cem anos de cinema, um século de rádio, quase o mesmo tempo de televisão e décadas de informática, a percepção e o aprendizado de cada geração tendem a ser cada vez menos lineares e cumulativos, como na escola. Desse modo, como poderia ser transmitido um único padrão de gosto legítimo? Ainda faria sentido falar em gosto no sentido sociológico atribuído por Pierre Bourdieu como balizador das práticas culturais no cenário contemporâneo?

A problemática torna-se mais específica quando se trata de pensar um país como o Brasil. Como sintetizou Renato Ortiz (1988, p.25): "devido à fragilidade do capitalismo existente [...] uma dimensão do mercado de bens simbólicos não consegue se expressar plenamente. Isso significa uma fraca divisão do trabalho intelectual e uma confusão de fronteiras entre as diversas áreas culturais." Após 


\section{Apresentação. Para além da distinção? \\ Desafios à abordagem bourdieusiana da formação social do gosto}

exemplificar com a interpenetração entre literatura e jornalismo, sociologia científica e discurso ideológico e, mesmo, teatro e televisão no início de sua implantação no Brasil, conclui: "entre nós as contradições entre uma cultura artística e outra de mercado não se manifestam de forma antagônica". (ORTIZ, 1988, p.29).

Isto significa que, no Brasil, o cenário cultural do qual se parte já é diferente do da Europa, particularmente o da França. Além da brutal diferença em termos de alfabetização, enquanto a França - certamente tentando manter sua hegemonia cultural sobre o mundo ocidental - ergueu todo tipo de barreiras legais e fiscais contra a exibição de conteúdos audiovisuais estrangeiros, sobretudo, estadunidenses, o Brasil implantou, com o apoio de dois regimes autoritários - o Estado Novo e a Ditadura Militar - aliados ao empresariado nacional e ao capital estrangeiro, o mercado nacional de bens simbólicos de massa. Na Era Vargas, o rádio, vale dizer, a Rádio Nacional conseguiu se expandir para todo o território nacional. No período militar, o Estado financiou a implantação de toda a infraestrutura do sistema de telecomunicações que não só integrou a nação, como a internacionalizou por meio dos satélites da empresa estatal Embratel. Ao longo dos anos 1970, o Brasil se situou entre os maiores mercados mundiais de produção e consumo cultural massivo, caso das indústrias fonográfica, televisiva, publicitária, dentre outras (ORTIZ, 1988). Nos anos do "milagre brasileiro" cerca de 20 milhões de aparelhos de televisão estavam presentes em torno de $3 / 4$ dos lares brasileiros. A cada novo surto econômico, este número se multiplicava. Isto ocorreu com o Plano Real, quando o número de aparelhos em uso praticamente dobrou, entre 1994 e 1998, saltando de algo em torno de 23 para 40 milhões de aparelhos em uso (BORELLI e PRIOLI, 2000). Repetiu-se com as políticas sociais do governo do Presidente Lula resultantes no aumento do poder aquisitivo dos estratos C e D (segundo o Sistema Brasil, utilizado pelas agências de mercado), quando milhões de brasileiros adquiriram seu primeiro aparelho.

À medida que a televisão se expandia, abrangendo todo o território nacional, sua programação se fragmentava cada vez mais. Os canais abertos especializaram sua programação em esportes, programas infantis etc. A TV paga no Brasil começa em 1988 com a Cable News Network (CNN) e a Music Television (MTV), duas emissoras do mercado audiovisual global (EUA), expandindo-se, ao longo da década seguinte, para dezenas de canais, nacionais e internacionais. A dispersão da audiência intensificou-se nos anos 1990 em razão do crescimento do número de aparelhos de televisão por domicílio. A maioria dos lares brasileiros já contava com mais de um aparelho desde o Plano Real, inclusive nos estratos C e D. No entanto, a TV paga até o início dos anos 2000 permanecia restrita aos estratos $\mathrm{A}$ e $\mathrm{B}$, ao menos, oficialmente. Na década seguinte, devido ao barateamento das operações e ao aumento do poder aquisitivo de um estrato mais popular de consumidores, sua expansão foi muito expressiva: “em 2013, 95\% dos novos clientes da TV paga 
eram da classe C ou D", as quais, somadas representavam $66 \%$ dos assinantes (EXAMEONLINE, 2013, n.p.).

A expansão das Tecnologias de Informação e Comunicação (TICs) no Brasil foi ainda mais espantosa. De acordo com a Pesquisa Nacional por Amostra de Domicílios (PNAD) do IBGE (2018), no final de 2016, o Brasil tinha 116 milhões de pessoas conectadas à internet, o que representava $64,7 \%$ da população com 10 ou mais anos de idade. Como era de se esperar, a distribuição regional é desigual, com a região Nordeste apresentando o menor índice, 52,3\%, e a Sudeste, o maior, $72,3 \%$. Embora os dados possam ser considerados baixos em relação a outros países, houve um grande salto a partir de 2005, quando a porcentagem de brasileiros com acesso à internet era de apenas 13,6\%. Certamente, um conjunto de fatores convergiu para este resultado, os quais necessitam ser mais bem investigados. Porém, um fato notório é a facilitação da aquisição do aparelho celular. Segundo a mesma pesquisa, em 2016, o celular era o dispositivo usado por $94,6 \%$ dos usuários para acessar a internet, sendo que $77,1 \%$ dos brasileiros possuíam algum aparelho desse tipo.

A questão torna-se ainda mais relevante pelo fato de a PNAD (IBGE, 2018) confirmar que a maior taxa de conectividade, $85 \%$, é encontrada na faixa etária tradicionalmente considerada como jovem, de 18 a 24 anos, contra $25 \%$ dos brasileiros acima dos 60 anos, considerados idosos. Todos os processos de mudança envolvem prioritariamente os jovens (como já tivemos oportunidade de apontar), como é o caso do público da MTV, dos movimentos que deram origem à cultura pop, dos estudantes que decidem abandonar a escola. Podemos estar diante de várias gerações de brasileiros, cuja socialização baseou-se mais nos meios de comunicação de massa e nas novas tecnologias de informação e comunicação como a internet, do que na cultura escolar, o que, como vimos, afetaria a interiorização das categorias de percepção e classificação do mundo que garantem mais do que o conhecimento, o reconhecimento da superioridade cultural do gosto e, portanto, da classe burguesa. Isto não significa que o poder simbólico ou a distinção cultural deixem de ter eficácia nas lutas de classe. É muito mais provável que novos cabedais, repertórios ou habilidades constituam novas formas de capital cultural.

\section{As contribuições neste dossiê}

A recepção de $A$ Distinção pelas Ciências Sociais no Brasil foi relativamente tardia, como se nota pelo fato de o livro ter sido traduzido para o português apenas em 2007. É provável que "o tema da reprodução da desigualdade por via da conformação social de padrões de gosto" tivesse pouco apelo entre cientistas sociais no Brasil, durante as décadas de 1980 e 1990, diante dos "desafios de superação de uma estrutura autoritária e do estabelecimento de uma nascente democracia". 


\section{Apresentação. Para além da distinção? \\ Desafios à abordagem bourdieusiana da formação social do gosto}

(BORTOLUCI; JACKSON; PINHEIRO FILHO, 2015, p.238). Nas últimas duas décadas, especialmente, muitos esforços têm sido feitos para incorporar o aparato analítico e conceitual dessa obra para tematizar aspectos da produção de desigualdades, da reprodução social e da formação de grupos na sociedade brasileira (PULICI; FERNANDES, 2019). ${ }^{6}$

Este dossiê se propõe a contribuir para esses debates. De diversas maneiras, os artigos que o compõem se debruçam sobre as potencialidades e limites contemporâneos dos conceitos de Pierre Bourdieu que relacionam práticas culturais, fronteiras simbólicas e aquisição de poder. No caso dos autores participantes, os estudos e pesquisas se referem ao Brasil, ocupando-se, em seu conjunto, das elites às classes populares, da esfera restrita da produção artística à esfera ampliada do entretenimento, dos mecanismos de distinção a outras dimensões das práticas culturais relacionadas à aquisição de poder.

O artigo de Ana Lucia de Castro aborda a construção de fronteiras simbólicas e laços de pertencimento no interior das classes populares, no momento em que parte dela é incorporada ao mercado de consumo e proclamada como a "nova classe média" brasileira. A análise baseia-se em pesquisa de campo realizada em um bairro da periferia do município de Santo André-SP junto aos moradores, todos ex-favelados, recém-transferidos para um condomínio da Companhia de Desenvolvimento Habitacional e Urbano do Estado de São Paulo (CDHU). Partindo da percepção dos moradores a respeito de suas novas condições de vida e do significado, muitas vezes ambíguo, atribuído ao pertencimento (ou não) à “classe média", a autora discute a aplicabilidade do conceito de habitus de Bourdieu para compreender essas trajetórias de vida de forma a incorporar "a dimensão subjetiva das práticas, sem desconsiderar as condicionantes estruturais que formatam as disposições culturais".

A incorporação de novos atributos ao capital cultural das elites paulistanas é o tema debatido por Miqueli Michetti. A autora percebe que o grau de internacionalização, há algum tempo, e a capacidade de dialogar com a diversidade, mais recentemente, passaram a ser avaliados positivamente na composição do repertório cultural dos alunos da Fundação Getúlio Vargas de São Paulo (FGV-SP). Em sua maioria, composto por indivíduos das classes altas e médias-altas, o alunado da FGV-SP, principal business school do país e, segundo a autora, amplamente certificada em todo o mundo, tem seu capital cultural fortemente apoiado nos capitais econômico e social. Como professora da instituição, valendo-se do método da observação participante, durante os anos 2012 e 2017, a autora reuniu uma série de informações que mostram a forma conflituosa assumida pela adoção dessas duas novas moedas na composição do capital cultural dos estudantes.

6 Para um balanço dessa produção, ver Bertoncelo, 2018. 
Retomando um argumento central à sociologia do gosto, segundo o qual as "escolhas são também recusas", Camila Gui Rosatti busca demonstrar que a preferência pela arquitetura moderna das "elites culturais" paulistanas, materializada na encomenda de casas projetadas por arquitetos de reconhecido valor, é também a "afirmação de um estilo de vida ao mesmo tempo cultivado e ousado" em oposição aos "modos de morar burguês", mais tradicionais e menos arriscados. Com base na análise de entrevistas com filhos dos encomendantes e de material documental de fontes distintas, a autora reconstrói as estratégias de transmissão intergeracional da herança cultural em "famílias de elite cultural", consumadas na posse e na manutenção de um patrimônio que é, ao mesmo tempo, imobiliário e simbólico. Os resultados da investigação apontam para a centralidade dos processos distintos no domínio das escolhas dos "modos e das maneiras de habitar" para "a reprodução social e familiar dos grupos sociais dominantes".

Ao analisar o consumo de perfume, Salete Nery aponta para a multidimensionalidade das práticas sociais e culturais. Visto como item supérfluo por natureza, a autora revela que, ao contrário, é considerado produto básico na cesta de consumo dos brasileiros, sobretudo, os das regiões norte e nordeste, as mais empobrecidas do país. Com o objetivo de compreender o que seria uma contradição ao que Pierre Bourdieu pensou em relação às classes populares e "os gostos de necessidade", ou seja, para entender melhor os motivos dessa forte relação dos nordestinos, em particular, os de baixa renda, com o hábito de perfumar-se, a autora principia com uma pesquisa baseada em questionários e entrevistas em profundidade na cidade de Cachoeira-BA, realizada nos anos de 1914-1915. Esta investigação lhe fornece indicações para buscar na própria história do Brasil, passando pela colonização, pela escravização dos negros, outras dimensões dessa prática cultural. Neste trajeto, a autora descobre, para além do bom gosto e do sentido de distinção, outros significados atribuídos à perfumação.

$\mathrm{O}$ artigo de Edson Farias remete a reflexão justamente para a esfera ampliada do mercado de bens simbólicos, o desfile das escolas de samba do Rio de Janeiro. Baseado em nove longas rodas de conversa com trabalhadores da Cidade do Samba, o autor encontra um mundo dotado de singularidade, com seus próprios princípios éticos e estéticos. No mundo da produção do "encantamento", os critérios para a atribuição de mérito e da concessão diplomas e títulos são diferentes, o que pode se constituir num espaço onde o "capital cultural" em circulação é de outro tipo, mas, no qual, curiosamente, revela o autor, as reivindicações e recusas são muito semelhantes às do campo da "arte legítima". 


\section{REFERÊNCIAS}

BENJAMIN, Walter. A obra de arte na era de sua reprodutibilidade técnica. In: Obras escolhidas: magia e técnica, arte de política. 5. ed. São Paulo: Brasiliense, 1993.

BENNETT, Tony et al. Culture, class, distinction. Londres: Routledge, 2009.

BERTONCELO, E. R. E. Consumo cultural e manutenção das distâncias sociais no Brasil. In: PULICI, C.; CERBONCINI, D. As lógicas sociais do gosto. São Paulo: Editora Unifesp, 2019.

. A força do simbólico na produção de desigualdades. In: MICELI, S.; MARTINS, C. B. Sociologia Brasileira Hoje. Volume II. São Paulo: Ateliê Editorial, 2018.

. Classes e práticas sociais. Revista Brasileira de Ciências Sociais, v. 28, n. 81, p.185-211, fev. 2013.

BOURDIEU, P. A Distinção: crítica social do julgamento. Porto Alegre: Zouk; São Paulo: Edusp, 2008.

. A Distinção: crítica social do julgamento. São Paulo: Edusp, 2007.

. O mercado de bens simbólicos. In A economia das trocas simbólicas. $2^{\mathrm{a}}$ edição. São Paulo: Perspectiva, 1982a.

. Sistemas de ensino e sistemas de pensamento. In: A economia das trocas simbólicas, $2^{\mathrm{a}}$ edição. São Paulo: Perspectiva, 1982b.

BORELLI, Silvia e PRIOLI, Gabriel. (orgs.) A deusa ferida: por que a Rede Globo não é mais a campeã absoluta de audiência. São Paulo: Summus, 2000.

BORTOLUCI, J. A.; JACKSON, L. C.; PINHEIRO FILHO, . Contemporâneo clássico: a recepção de Pierre Bourdieu no Brasil. Lua Nova, São Paulo, n. 94, p.217-254, 2015.

CHAN, T. W. Social Status and Cultural Consumption. Cambridge: Cambridge University Press, 2010.

CHAN, T. W.; GOLDTHORPE, J. Class and status: the conceptual distinction and its empirical relevance. American Sociological Review, v. 72, n. 4, p.512-532, 2007.

. Is there a status order in contemporary British society? Evidence from the occupational structure of friendship. European Sociological Review, v. 20, n. 5, p.383-401, 2004.

COUlangeOn, P. DUVAL, J. The Routledge Companion to Bourdieu's Distinction. Abingdon; Nova Iorque, Routledge, 2015. 
DUVAL, J. Estilos de Vida. In: CATANI, A. et al. Vocabulário Bourdieu. Belo Horizonte: Autêntica, 2017.

. Evolution of tastes in film and changes in field theory. In: COULANGEON, P. DUVAL, J. The Routledge Companion to Bourdieu's Distinction. Abingdon; Nova Iorque, Routledge, 2015.

ELIAS, Norbert. A sociedade de corte. $2^{\mathrm{a}}$. edição. Lisboa: Estampa, 1995.

. O processo civilizador: uma história dos costumes. v. 1. Rio de Janeiro: Zahar, 1990.

EXAMEONLINE. "95\% de novos clientes de TV por assinatura são classe C ou D". Publicado em 2013. Disponível em: <https://exame.abril.com.br/tecnologia/95-de-novosclientes-de-tv-por-assinatura-sao-classe-c-ou-d/?utm_source=email.> Acessado em: $11 \mathrm{dez}$. 2017.

GIDDENS, A. Modernidade e identidade. Rio de Janeiro: Jorge Zahar Editor, 2002.

GRIPSUD, J.; HOVDEN, J.; MOE, H. Changing relations: Class, education and cultural capital. Poetics, vol. 39, n. 6, p.507-529, dez. 2011.

HALLE, D. Bringing materialism back in: art in the houses of the working and middle classes. In: MCNALL, S.; LEVINE, R.; FANTASIA, R. (orgs.) Bringing class back in: contemporary and historical perspective. Oxford; São Francisco: Boulder/Westview Press, 1991.

HANQUiNeT, L; ROOSE, H.; SAVAGE, M. The Eyes of the Beholder: Aesthetic Preferences and the Remaking of Cultural Capital. Sociology, vol. 48, n. 1, p.111-132, 2014.

HARVEY, David. Condição pós-moderna. São Paulo: Loyola, 1993.

HOLT, D. Does cultural capital structure American consumption? Journal of Consumer Research, v. 25, p.1-25, junho 1998.

HUYSSEN, Andreas. Memórias do modernismo. Rio de Janeiro: Editora UFRJ, 1997. . Mapeando o pós-moderno. In HOLANDA, Heloísa Buarque (org.). Pós-modernismo e política. Rio de Janeiro: Rocco, 1991.

IBGE - Instituto Brasileiro de Geografia e Estatística. Pesquisa Nacional por Amostra de Domicílios Contínua: Pnad C. Publicada em 21 de fevereiro de 2018.

JARNESS, V. Modes of consumption: from "what" to "how" in cultural stratification research. Poetics, v. 53, p. 65-79, dez. 2015. 


\section{Apresentação. Para além da distinção? \\ Desafios à abordagem bourdieusiana da formação social do gosto}

KARADEMIR, I.; WARDE, A. The cultural omnivore thesis: methodological aspects of the debate. In: HANQUINET, Laurie; SAVAGE, Mike. Routledge International handbook of the sociology of art and culture. Londres, Nova York: Routledge, 2016.

LAHIRE, B. Cultural dissonances: the social in the singular. In: HANQUINET, Laurie; SAVAGE, Mike. Routledge International handbook of the sociology of art and culture. Londres, Nova York: Routledge, 2016.

. From de habitus to an individual heritage of dispositions. Towards a sociology at the level of the individual. Poetics, 31, v.5, n. 6, p.329-355, 2003.

LAMONT, M.; MOLNÁR, V. The study of boundaries in the Social Sciences. American Review of Sociology, vol. 28, p.167-195, 2002.

. Money, morals and manners: the culture of the French and the American middle class. Chicago: The University of Chicago Press, 1992.

LAREAU, A.; WEININGER, E. Cultural capital in educational research: A critical assessment. Theory and Society, vol. 32, n. 5-6, p. 567-606, dez. 2003.

LIZARDO, O.; SKILES. S. After omnivorousness: Is Bourdieu still relevant? In: HANQUINET, L.; SAVAGE, M. (orgs.), Routledge Handbook of the Sociology of Art and Culture. Abingdon; Nova Iorque, Routledge, 2016.

MIRA, Maria Celeste. O leitor e a banca de revistas: a segmentação da cultura no século XX. São Paulo: Olho D'Água/ Fapesp, 2001

ORTIZ, Renato. Mundialização e cultura. São Paulo: Brasiliense, 1994.

A Moderna Tradição Brasileira: cultura brasileira e indústria cultural. São Paulo: Brasiliense, 1988.

PEREIRA, J. V. B. Classes e culturas de classe das famílias portuenses: classes sociais e modalidades de estilização da vida na cidade do Porto. Porto: Afrontamento, 2005.

PETERSON, Richard. Problems in comparative research: the example of omnivorousness. Poetics, vol. 33, n. 5-6, pp. 257-282, 2005.

PETERSON, Richard A.; KERN, Roger M. Changing highbrow taste: From snob to omnivore. American Sociological Review, vol. 61, p.900-907, 1996.

PETERSON, Richard; SIMKUS, Albert. How musical tastes mark occupational status groups. In: LAMONT, Michèle; FOURNIER, Marcel (orgs.). Cultivating differences: Symbolic boundaries and the making of inequality. Chicago: The University of Chicago Press, 1992. 
PRIEUR. A.; SAVAGE, M. Emerging forms of cultural capital. European Societies, v. 15, n. 2, p.246-267, 2013.

. Updating cultural capital theory: A discussion based on studies in Denmark and in Britain. Poetics, vol. 39, n. 6, p.566-580, 2011.

PULICI, Carolina. A alimentação solene e parcimoniosa: práticas gastronômicas como fonte de distinção das elites brasileiras. Revista Ecopós, vol. 17, n. 3, p.1-15, 2014.

. O gosto dominante como gosto tradicional: preferências e aversões estéticas das classes altas de São Paulo. Novos Estudos Cebrap, São Paulo, n. 91, p.123-139, nov. 2011.

REEVES, A. Age-period-cohort and cultural engagement. In: HANQUINET, L.; SAVAGE, M. (orgs.), Routledge Handbook of the Sociology of Art and Culture. Abingdon; Nova Iorque, Routledge, 2016.

ROOSE, H. Signs of 'Emerging' Cultural Capital? Analysing Symbolic Struggles Using Class Specific Analysis. Sociology, vol. 49, n. 3, p.556-573, 2015.

SALLUM, B.; BERTONCELO, E. R. E. Classes Sociais. In: CATANI, A. et al. Vocabulário Bourdieu. Belo Horizonte: Autêntica, 2017.

SARLO, Beatriz. Culturas populares, velhas e novas. In: Cenas da vida pósmoderna: intelectuais, arte e vídeo-cultura na Argentina. Rio de Janeiro: Editora UFRJ, 1997.

SAVAGE, M. Class analysis and social transformation. Buckingham: Open University Press, 2000.

SAVAGE, M. et al. A New Model of Social Class? Findings from the BBC's Great British Class Survey Experiment. Sociology, vol. 47, n. 2, p.219-250, 2013.

SIBILIA, Paula. Redes ou paredes: a escola em tempos de dispersão. Rio de Janeiro: Contraponto, 2012.

SIMMEL, Georg. Estilo de vida. In Filosofia del dinero. Madri: Instituto de Estudios Políticos, 1977.

SKEGGS, B. Class, self, culture. Londres: Routledge, 2004.

SOMBART, Werner. Lujo y Capitalismo. Madri: Ediciones Sequitur, 2009.

STEWART, S. A Sociology of Culture, Taste and Value. Basingstoke; Nova Iorque, Palgrave Macmillan, 2013.

VANDENBERGHE, F. Globalização e individualização na modernidade tardia. Uma introdução teórica à sociologia da juventude. Mediações: Revista de Ciências Sociais, Londrina, v. 19, n. 1 p.265-316, jul. 2014. 
VEBLEN, Thorstein. A teoria da classe ociosa. São Paulo: Ed. Victor Civita, 1985.

VILLAS BÔAS, Glaucia. Ascese e prazer. Weber x Sombart. In Lua Nova. Revista de Cultura e Política. São Paulo, n. 52, p.173-196, 2001.

WARNKE, Martin. O artista da corte: os antecedentes dos artistas modernos. São Paulo: Edusp, 2001.

WILLIAMS, Raymond. Cultura e sociedade: 1780-1950. São Paulo: Companhia Editora Nacional, 1969.

WEBER, Max. Economia e Sociedade: fundamentos da sociologia compreensiva. Brasília, DF: Editora da UnB, 1991. 
